\title{
Evaluation of the diagnostic value of serum level of total bilirubin in patients with suspected acute appendicitis
}

\author{
Mohammad Reza Motie ${ }^{1}$, Minoosadat Mousavi Nik ${ }^{2}$, Malihe Gharaee ${ }^{2}$
}

${ }^{1}$ M.D, Senior Lecturer, Associate Professor of Surgery, Surgical Oncology Research Center, Imam Reza Hospital, Faculty of Medicine, Mashhad University of Medical Sciences, Mashhad, Iran

${ }^{2}$ M.D, Lecturer, Family Doctor, Mashhad University of Medical Sciences, Mashhad, Iran

\section{Type of article: Original}

\begin{abstract}
Introduction: Clinical diagnosis of acute appendicitis still remains a problem. Delays in diagnosis of acute appendicitis may cause perforation and septic peritonitis which result in increasing morbidity and mortality. The aim of this study was to determine the sensitivity, specificity and the diagnostic value of total serum bilirubin levels as a predictor of acute appendicitis.

Methods: In this cross-sectional study, patients who underwent appendectomy with the diagnosis of acute appendicitis from April 2012 to March 2013 at Emam Reza Hospital in Mashhad (Iran) were enrolled. Serum bilirubin -Total and Direct-, were measured. Then based on the final pathologic reports, patients were categorized into five groups of normal appendix, chronic inflammatory changes, acute appendicitis, gangrenous and/or necrotic changes, and perforated appendicitis. Independent sample t-test, ANOVA, and Chi-square test were used for data analysis by SPSS version 16.

Results: There were 174 patients studied, (117 male, 57 female) with a mean age of $27.15 \pm 0.7$ years. All of the patients had rebound tenderness; $75.3 \%$ had nausea, $58.6 \%$ had anorexia and $21.3 \%$ had fever. The histological reports of all patients showed $76.4 \%$ acute appendicitis. Analyzing p-values for SGPT, SGOT, WBC was $(\mathrm{p}=0.903)$ and differential count was $(\mathrm{p}=0.959)$. The study showed no significant difference between the pathological groups. However, there were no significant differences in serum total bilirubin levels between the pathological groups. Total bilirubin showed sensitivity of $48 \%$ and specificity of $61 \%$ in the diagnosis of acute appendicitis. Total serum bilirubin more than $0.85 \mathrm{mg} / \mathrm{dl}$ was the cut-off value with the best performance for diagnosis of appendicitis.
\end{abstract}

Conclusion: Bilirubin levels are reliable, sensitive and specific to diagnosis and a prediction of complicated appendicitis.

Keywords: Bilirubin, Appendicitis, Diagnosis, Complication

\section{Introduction}

Acute Appendicitis is the most frequent cause of abdominal pain which requires emergency surgery (1). Appendectomy for acute appendicitis is the most commonly performed emergency operation in the world; seven percent of all people undergo appendectomy for acute appendicitis during their lifetime (2). The diagnosis of acute appendicitis is based primarily on clinical symptoms and physical findings. Numerous scoring systems, incorporating clinical features and lab results, have been designed to assist the diagnosis, e.g. the Alvarado score, as the most popular one. Scores are based on clinical presentations, leukocyte count and/or C-reactive protein, and concentrate on the diagnostic calculation of appendicitis in a primary clinical situation (3-5). Radiologic investigations, such as CT scan, MRI or ultrasonography, confirm the diagnosis of appendicitis and its complications with high sensitivity and specificity, however they can be very costly and time-consuming, also, radiation could have long term adverse effects especially in pediatric patients; furthermore, they are not always

\section{Corresponding author:}

Associate Professor Dr. Mohammad Reza Motie, Surgical Oncology Research Center, Imam Reza Hospital, Mashhad, Iran. Tel: +98.5138519868, Fax:+98.5118525255, E-mail: motiem@mums.ac.ir

Received: March 19, 2016, Accepted: February 22, 2017, Published: April 2017 iThenticate screening: February 22, 2017, English editing: March 05, 2017, Quality control: March 10, 2017

(C) 2017 The Authors. This is an open access article under the terms of the Creative Commons Attribution-NonCommercialNoDerivs License, which permits use and distribution in any medium, provided the original work is properly cited, the use is non-commercial and no modifications or adaptations are made. 
available in emergency units and their routine use has not been shown to reduce the rate of negative appendectomies. Thus, we must rely on the clinic and laboratory tests to suspect appendicitis and estimate its extent, before relying on radiological examinations (2,6-9). Despite being the most common surgical emergency, and even after all these diagnostic tests, proper diagnosis and optimal management of acute appendicitis is very difficult, considering that there may not be classical symptoms and signs of appendicitis all the time, and different clinical signs and symptoms always mimic the diagnosis of acute appendicitis. Therefore, acute appendicitis remains the most commonly misdiagnosed surgical emergency and sometimes, either the diagnosis is missed resulting in complications such as appendiceal perforation or abscess formation, or the patient's normal appendix is removed, both leading to increase in mortality and morbidity $(1,4,10-13)$. The rate of perforated appendicitis in adults has been reported as between 17 to $20 \%$ (14). Perforated appendicitis has early and long-term complications; it is known to be the main cause of postoperative morbidity and prolonged hospital stays in these patients $(2,15,16)$. Morbidity following perforated appendicitis includes wound infection, bacterial peritonitis, intra-abdominal abscess formation, postoperative intestinal obstruction and prolonged ileus (10). No single clinical or laboratory test has been identified in order to reliably predict acute appendicitis or appendiceal perforation. Furthermore, none of the scoring systems evaluate the risk of appendiceal perforation (17). Accordingly, a simple, cheap and available test with an acceptable sensitivity, specific for acute appendicitis and its complications, in combination with clinical findings, is needed to make the diagnosis of AA, to anticipate its extent and severity, and to decide appropriate management $(1,2,18)$. However the diagnostic and discriminatory value of some blood markers, such as C-reactive protein (CRP), and white blood cell (WBC) count, had been extensively addressed in the former studies (19-22), and are currently applicable in scoring systems (5). In recent years, studies have emerged to show that serum bilirubin levels could indicate patients with acute appendicitis (23). Some studies have also formulated that hyperbilirubinemia can be associated with perforation and severity of the appendicitis $(3,18,24-27)$. Elevated serum bilirubin levels can be explained by the invasion of the Gram-negative bacteria to the appendix, leading to direct invasion or translocation of the germs in the portal system and the liver, interfering with bilirubin excretion through bile ducts by endotoxin action. So these markers, along with clinical presentation, can be used to improve preoperative diagnosis of acute appendicitis as well as prediction of its rupture as a new severity marker $(1,2,23)$. The aim of this study was to determine the sensitivity, specificity and the diagnostic value of total serum bilirubin levels as preoperative diagnostic/severity marker of acute appendicitis, on a series of patients with suspected acute appendicitis which underwent appendectomy later in the course of treatment.

\section{Material and Methods \\ 2.1. Study setting}

In this cross-sectional study, 174 patients, who were admitted to the emergency unit of Imam Reza hospital in Mashhad between April 2012 and March 2013 with clinical diagnosis of acute appendicitis, were included in this case series study.

\subsection{Selection criteria}

Patients with suspected acute appendicitis over 18 years old were included. Exclusion criteria were: 1) hepatobiliary diseases associated with hyperbilirubinemia, 2) hemolytic diseases, 3) history of alcoholism, 4) certain infectious diseases, 5) we excluded these patients because their diseases affect the serum bilirubin. All patients with suspected acute appendicitis were based on the Alvarado scoring system and if aged $>18$ years, were eligible for inclusion and underwent appendectomy in the general surgery department of Imam Reza hospital. Patients with any previously known liver disease (viral hepatitis, cirrhosis, Gilbert's disease, Dubin-Johnson syndrome, benign recurrent intrahepatic cholestasis and other documented biliary, hemolytic or liver diseases associated with hyperbilirubinaemia), risk factors for hepatic disease such as alcoholism and signs of infection which could explain elevated serum bilirubin levels, were excluded from the study

\subsection{Data collection and laboratory methods}

All the samples obtained during the appendectomy were sent to the pathology department for histopathological analysis. Ten $\mathrm{ml}$ of venous blood samples were obtained at the time of admission, and circulating levels of CRP, WBC, differential leukocytes count, total and direct bilirubin, SGOT and SGPT, were measured. As stated by our institutional laboratory, normal values were considered for $\mathrm{WBC}$ at $<11,000 / \mathrm{mm}^{3}$, for TB when levels were from 0 to $1.2 \mathrm{mg} / \mathrm{dl}$, and for CRP when levels were from $0-10 \mathrm{mg} / \mathrm{l}$. Each patient provided demographic and clinical information including age, gender, and the presence of fever, nausea/vomiting, anorexia, tenderness and rebound tenderness symptoms. Eligible participants were classified into groups based on final pathologic reports for appendix and surgical findings: Group1, having no abnormal pathologic findings; Group 2, presence of nonspecific 
chronic inflammatory changes; Group 3, evident acute inflammatory changes; Group 4, gangrenous and/or necrotic changes; and Group 5, perforated appendicitis.

\subsection{Statistical analysis}

All statistical analyses were performed using SPSS 16.0 for Windows (SSPS Inc., Chicago, IL, USA). Data were analyzed by Kolmogorov-Smirnov, unpaired t-test, Mann-Whitney U test, Kruskal-Wallis test, one-way analysis of variance (ANOVA), Chi square, and Fisher's exact test. In order to compare the sensitivity and specificity of the test variables WBC, CRP, TB, and their application when predicting perforated appendicitis, receiver-operating characteristic (ROC) curves were created for each endpoint. Two-sided p-values not greater than 0.05 were considered to show statistical significance for all statistical tests. When the area below the curve is nearer to 1.0 , it signifies a greater sensitivity and specificity; while an area below the curve, nearer to 0.5 , signifies a poorer sensitivity and specificity, confidence intervals of $95 \%$ were calculated. The best cutoff values with the highest sensitivity and specificity were established as the test variables.

\subsection{Research ethics}

This study was approved by the ethics committee of Mashhad University of Medical Sciences. (No. 900708). All participants gave full informed written consent, which included consent for biomarker analysis prior to inclusion into the study. Participation in this study was voluntary, and participants could exclude themselves at any time. All names (Number, patient name on the questionnaire and follow patients with file number) and information taken from the patient during the study, will remain confidential and the results will be published as a whole. If individual results are necessary, participants' anonymity will remain.

\section{Results}

A total of 174 patients were enrolled in the study. The mean age of all patients was $27.15 \pm 0.7$ years; most of the patients were between 21 to 40 years. The sex distribution of the participants was $117(67.3 \%)$ male to 57 (32.7\%) female patients. Analysis of the data distribution by the Kolmogorov-Smirnov test, showed that age, clinical and laboratory variables were not normally distributed. Therefore, Kruskal-Wallis non-parametric test was used to statistically analyze the variables that were not normally distributed. Considering the clinical criteria of the Alvarado scoring system, all patients $(100 \%)$ had rebound tenderness; 131 patients $(75.3 \%)$ had nausea, $102(58.6 \%)$ and 37 $(21.3 \%)$ cases presented with anorexia and fever respectively. Histological examination reports revealed that out of the 174 appendix specimens: Most of them, 76.4\% (133 samples) were reported as acute appendicitis (group 3); $0.6 \%(1), 13.9 \%(24), 8.5 \%$ (15) and $0.6 \%$ (1 sample) were categorized in the groups $1,2,4$ and 5 respectively. The percentage of each clinical criterion of Alvarado score within different pathological groups is summarized in Table 1. There was no statistically significant difference, between the pathologically divided groups, considering the presence of nausea $(p=0.724)$, anorexia $(p=0.69)$, fever $(p=0.053)$. Blood analysis results showed that, $66.7 \%$ of patients had leukocytosis (WBC $>11000$ ) and $90.8 \%$ of patients had shift to the left (neutrophil $>70 \%$ ). The mean serum total bilirubin level was $1.01 \pm 0.04$, mean CRP level was $9.72 \pm 0.39$ and mean circulating levels of SGOT and SGPT were $23.25 \pm 0.67$ and $17.36 \pm 0.64$, all of which were within normal limits. Analyzing values for SGPT levels $(p=0.106)$, SGOT levels $(p=0.427)$, WBC $(p=0.903)$ and differential count $(p=0.959)$, no statistically valuable difference was considerable between the patients in the five pathological groups. However, serum total bilirubin levels $(p=0.044)$, direct bilirubin $(p=0.032)$ and CRP $(p=0.047)$ had a significant difference between the different pathological groups. The ROC curve for total bilirubin showed sensitivity of $48 \%$ and specificity of $61 \%$ for prediction of the severity of acute appendicitis. Total serum bilirubin more than $0.85 \mathrm{mg} / \mathrm{dl}$ was the cut-off value with the best performance for prediction of perforated appendicitis (Figure 1).

Table 1. The percentage of each clinical criterion of Alvarado score within pathological group

\begin{tabular}{|l|l|l|l|l|l|}
\hline $\begin{array}{l}\text { Variables, } \mathrm{n} \\
(\%)\end{array}$ & $\begin{array}{l}\text { Normal } \\
\text { appendix } \\
\text { group }(\mathrm{n}=1)\end{array}$ & $\begin{array}{l}\text { Chronic } \\
\text { inflammatory } \\
\text { changes group } \\
(\mathrm{n}=24)\end{array}$ & $\begin{array}{l}\text { Acute } \\
\text { appendicitis } \\
\text { group } \\
(\mathrm{n}=133)\end{array}$ & $\begin{array}{l}\text { Gangrenous and/or } \\
\text { necrotic changes } \\
\text { group } \\
(\mathrm{n}=15)\end{array}$ & $\begin{array}{l}\text { Perforated } \\
\text { appendicitis } \\
\text { group } \\
(\mathrm{n}=1)\end{array}$ \\
\hline Nausea & $1(100 \%)$ & $19(79.1 \%)$ & $100(75.1 \%)$ & $10(66.6 \%)$ & $1(100 \%)$ \\
\hline Fever & 0 & $4(16.6 \%)$ & $25(18.8 \%)$ & $8(53.3 \%)$ & 0 \\
\hline Anorexia & 0 & $15(62.5 \%)$ & $78(58.64 \%)$ & $8(53.3 \%)$ & $1(100 \%)$ \\
\hline $\begin{array}{l}\text { Rebound } \\
\text { tenderness }\end{array}$ & $1(100 \%)$ & $(100 \%)$ & $(100 \%)$ & $(100 \%)$ & $(100 \%)$ \\
\hline
\end{tabular}




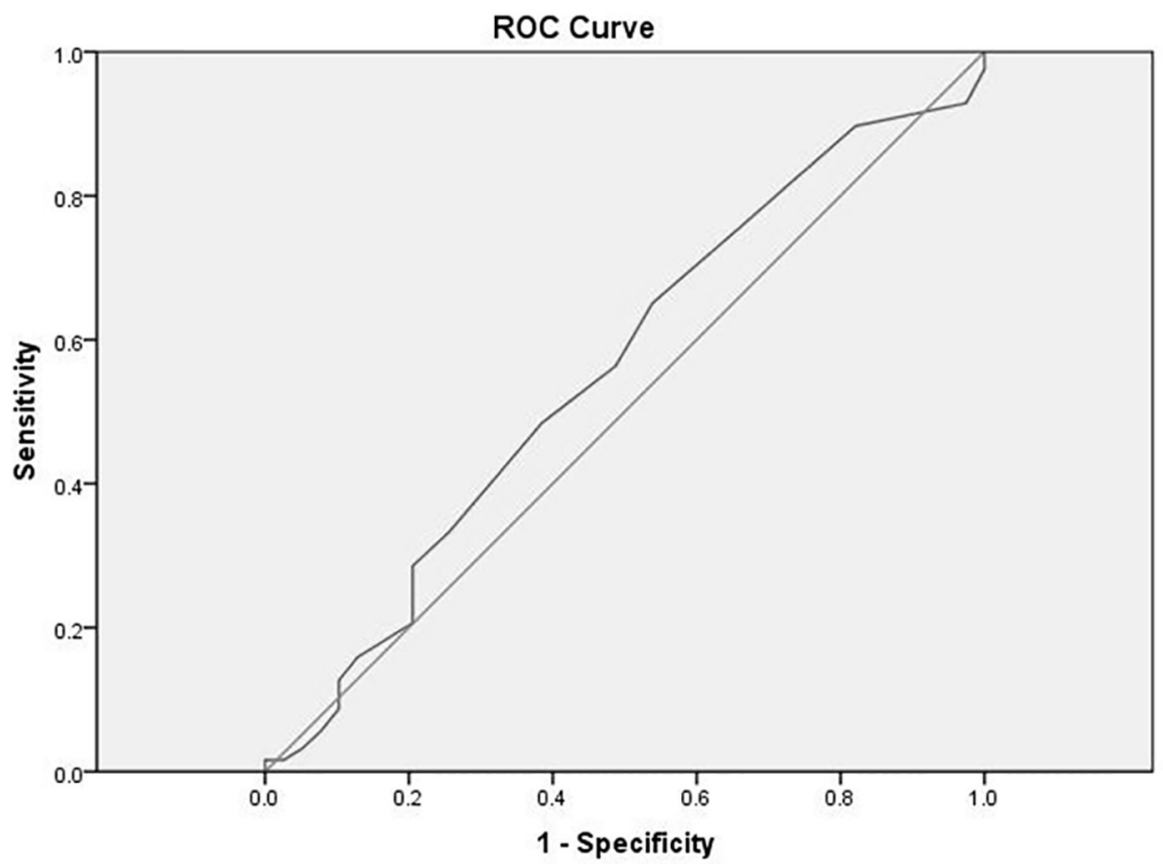

Figure 1. ROC Curve-specificity and sensitivity for prediction of the severity of acute appendicitis

\section{Discussion}

In emergency units, diagnosing appendicitis is mainly done through symptomatic history and clinical evaluation. Studies conducted before, mainly demonstrated a significant p-value and a considerable sensitivity and specificity for clinical signs and symptoms to diagnose appendicitis and to perform an appendectomy $(1,17,28)$. Anderson et al. in a meta-analysis also showed that clinical assessment and inflammatory markers were among the strongest discriminators of appendicitis (19). In our study, there was no statistically significant difference between the pathologically divided groups, considering the presence of nausea $(\mathrm{p}=0.724)$, anorexia $(\mathrm{p}=0.69)$, fever $(\mathrm{p}=0.053)$ and rebound tenderness $(\mathrm{p}=0.999)$. However, a raised white blood cell $(\mathrm{WBC})$ is not specific for appendicitis (18), leukocytosis and shift to the left, as laboratory criteria of Alvarado scoring, had been previously considered as key elements in diagnosing appendicitis with a high sensitivity $(20,23)$. Their importance as predictors of perforated appendicitis had been shown to be low in studies conducted before $(3,29)$. Analyzing values for WBC $(\mathrm{p}=0.903)$ and differential count $(\mathrm{p}=0.959)$, no statistically valuable difference was considerable between the patients in the five pathological groups in our study. Our study showed no statistically significant difference between pathological groups in the levels of ALT and AST. Studies regarding the importance of ALT and AST in diagnosing acute appendicitis and predicting perforated appendicitis are scarce and conflicting $(1,17)$. CRP is currently a wellestablished, sensitive, although unspecific marker in sepsis (30). Although the level of CRP is not significantly increased among patients suffering from acute appendicitis, the patients with perforated appendicitis may have a significant elevation of CRP levels compared to uncomplicated appendicitis $(17,31)$. In this study, CRP levels $(p=$ 0.047) had a significant difference between the different pathological groups. These results were consistent with most of the studies which have been done before. A study conducted by Beltran et al. showed a high sensitivity and low specificity for CRP to predict perforated appendicitis. They also concluded that CRP performed better than any other inflammatory marker, laboratory test, clinical variable, or SIRS to predict perforated appendicitis (6). These results were repeated by Panagiotopoulou et al. and Käser et al. (13, 32). In Anderson's study, inflammatory markers including CRP was as strong as clinical symptoms to predict advanced appendicitis (19). Serum bilirubin levels rise in perforated appendicitis just like in sepsis of any other cause, because of hepatic dysfunction during sepsis and it has therefore been suggested that bilirubin should be included in the assessment of such patients $(3,18$, 33). In the present study, serum total bilirubin levels $(\mathrm{p}=0.044)$, and direct bilirubin $(\mathrm{p}=0.032)$ had a significant difference between the different pathological groups. The ROC curve for total bilirubin showed sensitivity of $48 \%$ and specificity of $61 \%$ for prediction of the severity of acute appendicitis. Total serum bilirubin more than 0.85 $\mathrm{mg} / \mathrm{dl}$ was the cut-off value with the best performance for prediction of perforated appendicitis. In the study conducted by Chaudhary et al., total serum bilirubin including both direct and indirect was found to be significantly increased in cases of acute suppurative appendicitis, and was much higher in cases of gangrenous/perforated 
appendicitis (1). Findings from other studies are also following these results (1, 2, 23, 34-36). Sand et al. showed that hyperbilirubinaemia had a specificity of $86 \%$ for appendiceal perforation or gangrene, compared with a specificity of only $35 \%$ for CRP (27). Emmanuel et al. found that STB has a specificity of $88 \%$ and a positive predictive value of $91 \%$ for perforated acute appendicitis (18). Even a $100 \%$ specificity and $80 \%$ sensitivity has been reported for TSB by Khan et al. (4). Estrada et al. also showed that bilirubin levels of more than $1 \mathrm{mg} / \mathrm{dl}$ has a threefold risk of perforated appendicitis (26). Although, some studies showed no diagnostic value for bilirubin in the prediction of perforated appendicitis $(6,13)$. Bilirubin and no other serum marker, is sufficient alone in identifying patients with acute appendicitis and prediction of perforated appendicitis and it's useful only in combination with other factors such as clinical symptoms and other blood markers $(13,25)$, or bilirubin significance as a marker could be increased when combined with other markers (17). The predictive values of WBC and CRP also improve when combined, and appendicitis is unlikely when both WBC and CRP are within the normal range (13, 37, 38). Therefore none of these markers have a definitive diagnostic value and there is a greater chance of diagnosing acute appendicitis when using a combination of multiple blood markers compared to using only one $(17,23)$. In general, these biomarkers have had high specificity but low sensitivity. When biomarkers are combined, the specificity increases, but there is little influence on sensitivity. Therefore, relevant biomarkers, whether combined or alone, cannot be used to determine differentials, but rather add further support to a patient's clinical appearance and symptomatic history.

\section{Study limitations and strengths}

This study is limited by its limited number of patients so this mandates larger studies in the future. Also, detailed histories and investigations to exclude all patients with pre-existing liver or hemolytic diseases and other exclusion criteria were not taken. However, in this study, we used the cooperation of young people, and in collaboration with research centers and laboratories of Mashhad University of Medical Sciences, the project process was facilitated.

\section{Conclusions}

Although diagnosis of acute appendicitis is a problem for surgeons, in the current study we showed that a bilirubin level is a reliable factor to predict complicated appendicitis. This marker, along with the other markers including WBC, CRP and clinical presentation are more reliable and indeed more sensitive and specific to predict complicated appendicitis. More studies with larger study population are needed in the future to conclude more precisely in this matter.

\section{Acknowledgments:}

Our Research Project was partially or fully sponsored by Mashhad University of Medical Sciences with grant number (900708). The results described in this paper constituted as a part of a MD thesis submitted by the third author to Mashhad University of Medical Sciences. The study was supported by the vice chancellor for research at Mashhad University of Medical Sciences. The authors would like to gratefully acknowledge Ms. A. Ziaeemehr for editing the manuscript.

\section{Conflict of Interest:}

There is no conflict of interest to be declared.

\section{Authors' contributions:}

All authors contributed to this project and article equally. All authors read and approved the final manuscript.

\section{References:}

1) Chaudhary P, Kumar A, Saxena N, Biswal UC. Hyperbilirubinemia as a predictor of gangrenous/perforated appendicitis: a prospective study. Ann Gastroenterol. 2013; 26(4): 325-31. PMID: 24714371, PMCID: PMC3959475.

2) Vaziri M, Pazouki A, Tamannaie Z, Maghsoudloo F, Pishgahroudsari M, Chaichian S. Comparison of preoperative bilirubin level in simple appendicitis and perforated appendicitis. Med J Islam Repub Iran. 2013; 27(3): 109-12. PMID: 24791119, PMCID: PMC3917482.

3) Hong YR, Chung CW, Kim JW, Kwon CI, Ahn DH, Kwon SW, et al. Hyperbilirubinemia is a significant indicator for the severity of acute appendicitis. J Korean Soc Coloproctol. 2012; 28(5): 247-52. doi: 10.3393/jksc.2012.28.5.247. PMID: 23185704, PMCID: PMC3499425.

4) Khan S. The diagnostic value of hyperbilirubinemia and total leukocyte count in the evaluation of acute appendicitis. J Clin Diagn Res. 2009; 3(4): 1647-52. 
5) Alvarado A. A practical score for the early diagnosis of acute appendicitis. Ann Emerg Med. 1986; 15(5): 557-64. doi: 10.1016/S0196-0644(86)80993-3. PMID: 3963537.

6) Beltran MA, Mendez PE, Barrera RE, Contreras MA, Wilson CS, Cortes VJ, et al. Is hyperbilirubinaemia in appendicitis a better predictor of perforation than C-reactive protein? - a prospective study. Indian J Surg. 2009; 71(5): 265-72. doi: 10.1007/s12262-009-0074-8. PMID: 23133170, PMCID: PMC3452791.

7) Doria AS, Moineddin R, Kellenberger CJ, Epelman M, Beyene J, Schuh S, et al. US or CT for Diagnosis of Appendicitis in Children and Adults? A Meta-Analysis. Radiology. 2006; 241(1): 83-94. doi: 10.1148/radiol.2411050913. PMID: 16928974.

8) Raman SS, Lu DS, Kadell BM, Vodopich DJ, Sayre J, Cryer H. Accuracy of nonfocused helical CT for the diagnosis of acute appendicitis: a 5-year review. AJR Am J Roentgenol. 2002; 178(6): 1319-25. doi: 10.2214/ajr.178.6.1781319. PMID: 12034591.

9) Flum DR, McClure TD, Morris A, Koepsell T. Misdiagnosis of appendicitis and the use of diagnostic imaging. J Am Coll Surg. 2005; 201(6): 933-9. doi: 10.1016/j.jamcollsurg.2005.04.039. PMID: 16310698.

10) Noh H, Chang SJ, Han A. The diagnostic values of preoperative laboratory markers in children with complicated appendicitis. J Korean Surg Soc. 2012; 83(4): 237-41. doi: 10.4174/jkss.2012.83.4.237. PMID: 23091796, PMCID: PMC3467390.

11) Son CS, Jang BK, Seo ST, Kim MS, Kim YN. A hybrid decision support model to discover informative knowledge in diagnosing acute appendicitis. BMC Med Inform Decis Mak. 2012; 12: 17. doi: 10.1186/1472-6947-12-17. PMID: 22410346, PMCID: PMC3314559.

12) Andersson RE, Hugander A, Thulin AJ. Diagnostic accuracy and perforation rate in appendicitis: association with age and sex of the patient and with appendicectomy rate. Eur J Surg. 1992; 158(1): 37-41. PMID: 1348639.

13) Panagiotopoulou I, Parashar D, Lin R, Antonowicz S, Wells AD, Bajwa FM, et al. The diagnostic value of white cell count, C-reactive protein and bilirubin in acute appendicitis and its complications. Ann R Coll Surg Engl. 2013; 95(3): 215-21. doi: 10.1308/003588413X13511609957371. PMID: 23827295, PMCID: PMC4165248.

14) Flum DR, Morris A, Koepsell T, Dellinger EP. Has misdiagnosis of appendicitis decreased over time? a population-based analysis. Jama. 2001; 286(14): 1748-53. doi: 10.1001/jama.286.14.1748. PMID: 11594900.

15) Bickell NA, Aufses AH, Rojas M, Bodian C. How time affects the risk of rupture in appendicitis. J Am Coll Surg. 2006; 202(3): 401-6. doi: 10.1016/j.jamcollsurg.2005.11.016. PMID: 16500243.

16) Fike FB, Mortellaro VE, Juang D, Sharp SW, Ostlie DJ, St Peter SD. The impact of postoperative abscess formation in perforated appendicitis. J Surg Res. 2011; 170(1): 24-6. doi: 10.1016/j.jss.2011.03.038. PMID: 21550056.

17) Farooqui W, Pommergaard HC, Burcharth J, Eriksen JR. The diagnostic value of a panel of serological markers in acute appendicitis. Scand J Surg. 2015; 104(2): 72-8. doi: 10.1177/1457496914529273. PMID: 24737847.

18) Emmanuel A, Murchan P, Wilson I, Balfe P. The value of hyperbilirubinaemia in the diagnosis of acute appendicitis. Ann R Coll Surg Engl. 2011; 93(3): 213-7. doi: 10.1308/147870811X566402. PMID: 21477433 , PMCID: PMC3291137.

19) Andersson RE. Meta - analysis of the clinical and laboratory diagnosis of appendicitis. Br J Surg. 2004; 91(1): 28-37. doi: 10.1002/bjs.4464. PMID: 14716790.

20) Birchley D. Patients with clinical acute appendicitis should have pre-operative full blood count and Creactive protein assays. Ann R Coll Surg Engl. 2006; 88(1): 27-32. doi: 10.1308/003588406X83041. PMID: 16460636, PMCID: PMC1963644.

21) Körner H, Söreide JA, Söndenaa K. Diagnostic accuracy of inflammatory markers in patients operated on for suspected acute appendicitis: a receiver operating characteristic curve analysis. Eur J Surg. 1999; 165(7): 679-85. doi: 10.1080/11024159950189744. PMID: 10452263.

22) Vaughan-Shaw PG, Rees JR, Bell E, Hamdan M, Platt T. Normal inflammatory markers in appendicitis: evidence from two independent cohort studies. JRSM Short Rep. 2011; 2(5): 43. doi: 10.1258/shorts.2011.010114. PMID: 21637404, PMCID: PMC3105453.

23) Socea B, Carâp A, Rac-Albu M, Constantin V. The value of serum bilirubin level and of white blood cell count as severity markers for acute appendicitis. Chirurgia (Bucur). 2013; 108(6): 829-34. PMID: 24331322 . 
24) Nomura S, Watanabe M, Komine O, Shioya T, Toyoda T, Bou H, et al. Serum total bilirubin elevation is a predictor of the clinicopathological severity of acute appendicitis. Surg Today. 2014; 44(6): 1104-8. doi: 10.1007/s00595-013-0659-5. PMID: 23880964.

25) Giordano S, Pääkkönen M, Salminen P, Grönroos JM. Elevated serum bilirubin in assessing the likelihood of perforation in acute appendicitis: a diagnostic meta-analysis. Int J Surg. 2013; 11(9): 795-800. doi: 10.1016/j.ijsu.2013.05.029. PMID: 23732757.

26) Estrada JJ, Petrosyan M, Barnhart J, Tao M, Sohn H, Towfigh S, et al. Hyperbilirubinemia in appendicitis: a new predictor of perforation. J Gastrointest Surg. 2007; 11(6): 714-8. doi: 10.1007/s11605-007-0156-5. PMID: 17436050 .

27) Sand M, Bechara FG, Holland-Letz T, Sand D, Mehnert G, Mann B. Diagnostic value of hyperbilirubinemia as a predictive factor for appendiceal perforation in acute appendicitis. Am J Surg. 2009; 198(2): 193-8. doi: 10.1016/j.amjsurg.2008.08.026. PMID: 19306980.

28) Paulson EK, Kalady MF, Pappas TN. Clinical practice. Suspected appendicitis. N Engl J Med. 2003; 348(3): 236-42. doi: 10.1056/NEJMcp013351. PMID: 12529465.

29) Keskek M, Tez M, Yoldas O, Acar A, Akgul O, Gocmen E, et al. Receiver operating characteristic analysis of leukocyte counts in operations for suspected appendicitis. Am J Emerg Med. 2008; 26(7): 769-72. doi: 10.1016/j.ajem.2007.10.036. PMID: 18774040.

30) Póvoa P. C-reactive protein: a valuable marker of sepsis. Intensive Care Med. 2002; 28(3): 235-43. doi: 10.1007/s00134-002-1209-6. PMID: 11904651.

31) Grönroos JM, Grönroos P. Leucocyte count and C - reactive protein in the diagnosis of acute appendicitis. Br J Surg. 1999; 86(4): 501-4. doi: 10.1046/j.1365-2168.1999.01063.x. PMID: 10215824.

32) Käser SA, Fankhauser G, Willi N, Maurer CA. C-reactive protein is superior to bilirubin for anticipation of perforation in acute appendicitis. Scand J Gastroenterol. 2010; 45(7-8): 885-92. doi: 10.3109/00365521003728572. PMID: 20334601.

33) Brienza N, Dalfino L, Cinnella G, Diele C, Bruno F, Fiore T. Jaundice in critical illness: promoting factors of a concealed reality. Intensive Care Med. 2006; 32(2): 267-74. doi: 10.1007/s00134-005-0023-3. PMID: 16450099.

34) Khan S. Elevated serum bilirubin in acute appendicitis: a new diagnostic tool. Kathmandu Univ Med J. 2008; 6(2): 161-5. PMID: 18769079.

35) Atahan K, Üreyen O, Aslan E, Deniz M, Çökmez A, Gür S, et al. Preoperative diagnostic role of hyperbilirubinaemia as a marker of appendix perforation. J Int Med Res. 2011; 39(2): 609-18. doi: 10.1177/147323001103900230. PMID: 21672366.

36) Emmanuel A, Murchan P, Wilson I, Balfe P. The value of hyperbilirubinaemia in the diagnosis of acute appendicitis. Ann R Coll Surg Engl. 2011; 93(3): 213-7. doi: 10.1308/147870811X566402. PMID: 21477433, PMCID: PMC3291137.

37) Ortega-Deballon P, Ruiz de Adana-Belbel JC, Hernández-Matías A, García-Septiem J, Moreno-Azcoita M. Usefulness of laboratory data in the management of right iliac fossa pain in adults. Dis Colon Rectum. 2008; 51(7): 1093-9. doi: 10.1007/s10350-008-9265-9. PMID: 18484138, PMCID: PMC2887665.

38) Sengupta A, Bax G, Paterson-Brown S. White cell count and C-reactive protein measurement in patients with possible appendicitis. Ann R Coll Surg Engl. 2009; 91(2): 113-5. doi: 10.1308/003588409X359330. PMID: 19102827, PMCID: PMC2749345. 